\title{
Metropolitan Spillover Effects and Economic Growth of Non-Metropolitan Areas: Evidence from Indiana Counties
}

\author{
Litao Zhong, Ph.D. \\ School of Business and Economics \\ Indiana University East \\ 2325 Chester Blvd. \\ Richmond, Indiana 47374 \\ U.S.A. \\ E-mail: litzhong@iue.edu
}

Received: August 24, 2016 Accepted: September 8, 2016 Published: September 20, 2016

doi:10.5296/ijrd.v3i2.9938

URL: http://dx.doi.org/10.5296/ijrd.v3i2.9938

\begin{abstract}
This paper examines the importance of metropolitan spillover effects on the economic growth of non-metropolitan counties in the state of Indiana by using panel data from 2003 to 2013. I hypothesize that metro economic size and non-metro counties' locations, along with other metro social and economic factors, will have significant impact on non-metro counties' economic growth. Based on the results from the Random-effects Generalized Least Squares (GLS) and the population-averaged Generalized Estimating Equations (GEE) regressions, metro GDP and population have significant, positive impacts on non-metro counties' economic growth, while non-metro counties' locations (i.e., the distance to a metro county), metro K-12 school enrollment, the wage gap and the number of commuters between metro and non-metro areas have significant, negative effects on the economic growth of non-metro counties in Indiana. Some of the dummy variables also showed significant association with the non-metro counties' economic well-being.
\end{abstract}

Keywords: Metropolitan Factors, Spill-Over Effects, Regional Economic Growth

\section{Introduction}

It is well-known that metropolitan areas are the powerhouses of the U.S. economy. According to data from the United States Conference of Mayors, the nation's 381 metropolitan areas 
contain $86 \%$ of total U.S. non-farm employment, $90 \%$ of the country's real GDP, and $85.7 \%$ of the country's population (Note 1). Due to their significant contributions to the nation's economy, metropolitan areas in the U.S. have inevitably been the focus of a large amount of research. In contrast, the economic growth of non-metropolitan areas, including the micropolitan and rural counties, has been neglected.

Interestingly, unequal economic growth also exists among non-metro areas. Thus, a related question can be asked: why does a disparity exist among the non-metro counties' economic growth? Previous literature has offered some social and economic reasons to answer this question. For example, Deller et al. (2001) found that strong relationships exist between various socio-economic factors and local economic performance. The socio-economic factors ranged from amenity and quality of life characteristics to local characteristics. As such, they stated that rural areas endowed with key natural resource amenities appeared to capture economic growth and development more effectively.

In addition, research completed by Ring, Peredo, and Chrisman (2010) suggested that the success of business networks in rural areas enhanced the contributions that business ventures may make to rural areas' well-being. They argued that the extent to which the social structure of a rural community allowed for constructive conflict, inclusion, and permeability influenced the formation and development of business networks. The exploitation of business networks might create additional entrepreneurial opportunities through co-developments and spillovers. Similar studies focusing on the link between social capital and entrepreneurs' successes and the rural communities' development have also been completed by Besser and Miller (2013) and Poon, Thai, and Naybor (2012).

From an international perspective, Mao and Koo (1997) applied a data envelopment analysis approach to determine that technical progress was mostly attributed to Chinese rural areas' productivity growth. They noted that enhancing rural education and research and development would improve technical efficiency and productivity in rural areas and achieve economic growth. Fan, Hazell, and Thorat (2000) utilized a simultaneous equation model to regress Indian state-level data from 1970 to 1993. They concluded that, in order to reduce rural poverty and encourage rural economic growth, the Indian government should increase government spending on rural infrastructure, agricultural research, and education.

All of these findings are aimed toward endogenous factors related to non-metro counties' economic growth. Undoubtedly, endogenous factors play a key role in non-metro counties' well-being, but this research extends this scope to study exogenous or external factors. To this end, this paper tries to find whether exogenous factors, such as metro factors, are important for non-metro counties' economies? If so, what are the exogenous metro factors? This area of focus remains understudied in the literature. Most researchers have only examined the imbalanced economic growth between metro and non-metro areas (Beggs et al., 1996; Morrill et al., 1999; Ding, 2002; Fallad \& Patridge, 2007; Zenou, 2011). Although other studies have provided evidence of economic links between the metro areas and surrounding areas (Liu, Wang \& Wu, 2011; Eppler, Fritsche \& Laaks, 2015), they haven't clearly specified what metro factors are associated with non-metro areas' economies. As such, this study attempts to 
explain how metro counties economically influence non-metro counties. The economic power of metro counties apparently has eminent influence on their surrounding areas. As such, a non-metro county adjacent to at least one metro county should take advantage of the ripple effect from the metro county's economic power and should experience a notable growth rate when compared to its peers. Therefore, the purpose of this research is fill this gap in the literature as it offers an empirical study of the metropolitan spillover effect on determining non-metro counties' economic growth.

This paper is organized as follows. Section 2 provides a literature review and the formation of the hypotheses of study. Section 3 describes the data and methodology. Section 4 discusses the regression results and Section 5 contains a conclusion.

\section{Literature Review and Hypothesis Formation}

Many potential exogenous factors exist that might determine regional growth. In his book The Wealth and Poverty of Regions, Polese (2009) pointed out that location and size are the two most important factors for a region's growth in regard to wealth.

"If a place has both size and a propitious location, its potential will be greater than that of most other places in the nation. If it does not have one it should at least have the other. If a place has neither, the likelihood that it will generate high incomes is reduced..." (Page 29)

He also explained that "the corollary of size matters is that proximity to size - to urban centers - also matters." (Page 29) As this paper investigates the metropolitan spillover effects on other areas' economic growth, the factors of metro economic size and non-metro areas' locations that can be measured by the distance to the urban center clearly stand out.

Other researchers have also found that location/distance matters in regard to having an impact on rural areas' economies. According to Partridge and Rickman (2008), remote rural areas' poverty rates are positively associated with distances from larger metropolitan areas. As such, they stated that the urban spill-over effect might attenuate over distance, for example, distance may restrain the trade of goods with metro areas, reduce job commuting opportunities for rural residents, and reduce access to specialized urban services, which serve to decrease demand for rural workers. Mulligan (2013) also remarked the micropolitan areas that have substantial urban cores and enjoy nearness to large cities should continue to prosper, but those rural areas lacking in resources, amenities, and metropolitan proximity will face a bleak future. Based on the theoretical background discussed above, I hypothesize that:

H1: The metro economic size and distance between the metro and non-metro counties are significantly related to the non-metro county's economic growth, whereas the metro economic size shows positive impact and the distance has negative impact.

Metro economic power is not only measured by its dollar value of output, GDP, but can also be measured by other economic and social indicators, such as metro population. The well-known classic growth theory has firmly explained the positive nexus between population and growth (Smith, 1776; Malthus, 1798; Ricardo, 1817) to some extent. The 
classic growth theory postulated that output depends on the stock of capital, labor force, land, and the level of technology. In addition, the labor force is largely dependent of the rate of the population growth. More recent studies have confirmed the importance of population to economic growth (Simon, 1986; Mankiw, 1990). Thus, a densely populated metro area not only benefits its own economy, but also causes a positive ripple effect to its surrounding areas.

\section{H2: The metro population is significantly and positively related to the non-metro county's economic growth.}

In addition to population, the metro's education level, average wage levels, and labor mobility can also impact the spillover effects to non-metro areas. The importance of education and human capital has been widely tested as a key variable in the literature of economic growth (Romer, 1986; Krugman, 1991; Lucas, 2000; Frenken et al., 2007; Abel \& Gabe, 2011). For example, Lucas (1988) stated that individuals might not capture all of the benefits of their own education and human capital, causing some benefits to spillover to their colleagues and coworkers to cause more extensive impacts to the whole firm, industry, and economy.

On the international level, Fleisher et al. (2010) investigated the contribution of human capital to the total factor productivity (TFP) growth among different regions in China. They concluded that the dispersion in human capital and infrastructural capital was the main reason of regional inequality in China as the coastal provinces had a much larger positive spillover effect of human capital on TFP growth than any other region in China. I believe that such positive externality of education and human capital can also cross the metro boundary to influence the surrounding areas' businesses and economy. Therefore, the third hypothesis can be stated as follows:

H3: The metro K-12 school enrollment is significantly and positively related to the non-metro county's economic growth.

Higher human capital levels can be reflected as higher income and wage levels. According to Florida et al. (2008) human capital and occupational skills affect regional development through wages and income. They also found that the correlation coefficient for human capital and wages is 0.653 . Despite this evidence, it should be noted that direct studies on the relationship between the wage gap and regional economic growth is rare. Instead, most related studied have focused on the effect of income inequality on a country's economic growth, but the results are controversy. Both Kaldor (1960) and Kalecki (1971) concluded that inequality is good in regard to creating incentives and, therefore, good for growth. More recent studies have confirmed this relationship (Barro, 1999; Forbes, 1997; Li \& Zou 1998).

However, several other studies have unambiguously concluded that greater inequality retards the rate of growth (Alesina \& Rodrick, 1994; Perotti, 1996; Persson \& Tabellini, 1994). Built on these early studies, Aghion et al. (1999) showed that wealth inequality may be bad for growth for three reasons: (1) inequality reduces investment opportunities; (2) inequality worsens borrowers' incentives; and (3) inequality generates macroeconomic volatility. Since 
this article studies the impact of the wage gap upon non-metro economic growth, both positive and negative relationships seem possible. A larger gap between metro and non-metro areas will allow the metro areas to attract more skilled workers. As the metro area's economy grows, the positive spillover may extend to the non-metro areas, as explained in the first hypothesis. In contrast, unappealing wages in non-metro areas could also impede their growth due to a lack of the necessary human capital. According to the above discussion, I hypothesize:

H4: The wage gap between the metro and non-metro counties is significantly related to the non-metro's economic growth, but the relationship is ambiguous.

The wage gap between metro and non-metro areas could trigger labor mobility. People might choose to live in the non-metro areas, which usually have a lower living cost, and commute to the metro areas in order to pursue a higher paying job (Partridge, Ali, \& Olfert, 2010). Cheshire and Carbonaro (1996) showed that a strong positive relationship exists among the length of a commuting trip, income, and measures of human capital. Urban areas with higher income growth attract commuters from neighboring areas, thus increasing their workforce and total GDP.

Controversially, Goetz et al (2010) concluded that large numbers of commuters reduce the local income growth rate and having a longer commute time suppresses per capital income growth over time. As such, it seems that the commuting pattern might have both positive and negative impacts on the local economy. The more commuters who travel between the metro and non-metro areas, the stronger the economic ties between the two regions as wages earned and information brought from workplaces in the metro will likely benefit the economy where the commuters reside. On the other hand, more out-commuters from non-metro areas indicate economic distress in these areas, which forces people to seek employment in the nearby urban areas. Based on the analysis above, the following hypothesis can be derived:

H5: The number of commuters is significant to the non-metro's economic growth, but the sign of the relation is ambiguous.

\section{Data and Research Methodology}

In this section, I will test the relationship between the economic growth of non-metro counties in the state of Indiana and multiple metro factors. The data for this study was collected between 2003 and 2013 due to the data availability of all independent variables. The state of Indiana has 92 counties, of which 44 fall into one of 15 metropolitan areas (Note 2). Thus, the remaining 48 counties are defined as non-metro counties. According to data from Bureau of Economic Analysis, in 2013 the population of Indiana was 6,570,713, the average population of Indiana's 92 counties was 71421 with Marion County as the most populous $(928,349)$, and Ohio County $(6,035)$ the least. Regarding the economic size which is measured by the total personal income (TPI), Indiana's TPI was $\$ 252$ billion in 2013, the average TPI of all 92 counties was $\$ 2.7$ billion. Still Marion County took the top spot with $\$ 36$ billion and Ohio County ranked the 92th with $\$ 193$ million. 


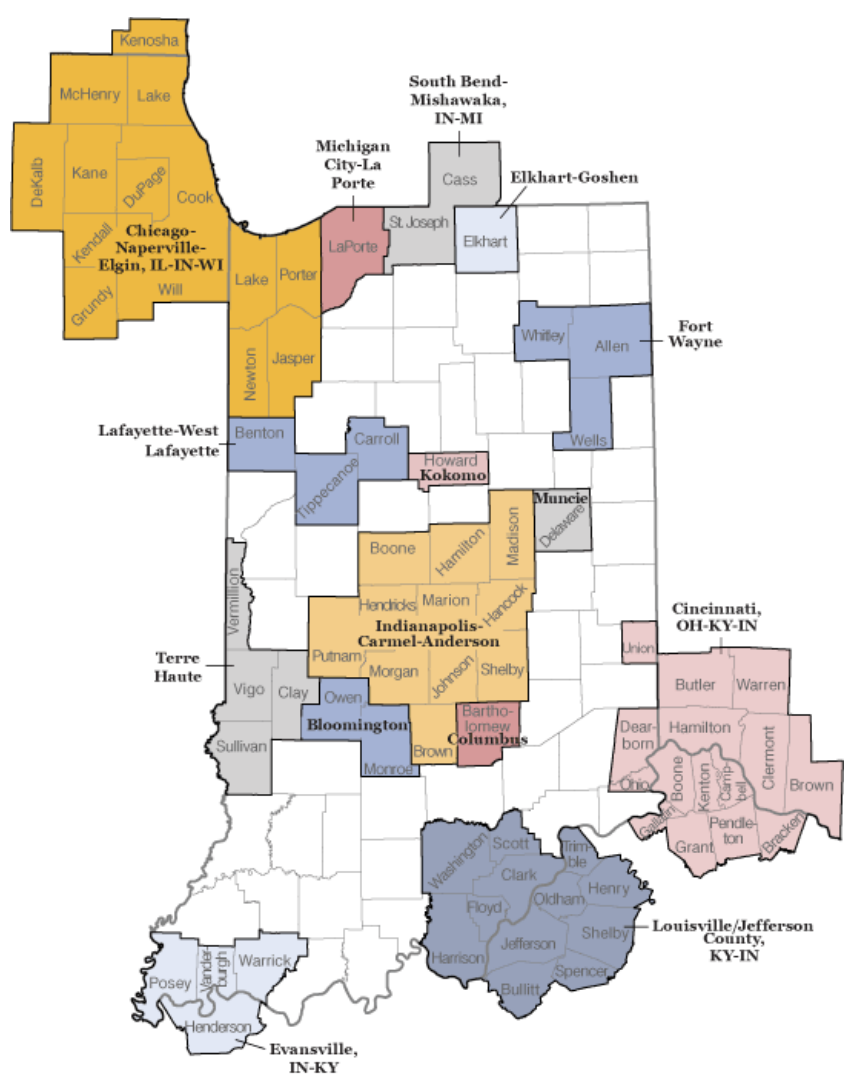

Figure 1. Indiana's Metropolitan Statistical Areas

In the regression models for this study, the dependent variable is the non-metro counties' total personal income. In addition, for the models, there are five time-variant independent variables, one time-invariant independent variable, and three dummy variables. The variable description, regression symbols, and data sources are listed in Table 1.

Table 1. List of variables, regression symbols, and data sources

Variables Symbols $\quad$ Data Source

\section{Dependent Variable}

Non-metro Total Personal Income NMTPI Analysis (BEA)

Independent Variables

$\begin{array}{lll}\text { Metro GDP } & \text { MGDP } & \text { Analysis (BEA) } \\ \text { Distance to Metro } & \text { DIS } & \text { Google Map }\end{array}$




$\begin{array}{lll} & \text { MPop } \quad \begin{array}{l}\text { Indiana Business Research Center (IBRC), } \\ \text { using Census Bureau data }\end{array} \\ \text { Metro Population } & & \\ \text { Metro School Enrollment } & \text { MSchEn } \quad \text { Indiana Department of Education }\end{array}$

United States Bureau of Labor Statistics

Wage Gap WageGaP (BLS)

Number of Commuters

COM

IBRC, using Indiana Department of Revenue data

\section{Dummy Variables}

Border with Metros $\quad$ BWM Google Map

Border with Large Metros

BWLM Google Map

Highway to Metros

Highway Google Map

I tested the hypotheses using the following model:

$$
\begin{gathered}
\mathrm{NMTPI}_{i, t}=\beta_{0}+\beta_{1} \mathrm{MGDP}_{i, t}+\beta_{2} \mathrm{DIS}_{i}+\beta_{3} \mathrm{MPop}_{i, t}+\beta_{4} M \mathrm{MShEn}_{i, t} \\
+\beta_{5} \text { WageGap }_{i, t}+\beta_{6} \mathrm{COM}_{i, t}+\beta_{7} \mathrm{BWM}_{i}+\beta_{8} \text { BWLM }_{i}+\beta_{9} \text { Highway }_{i}+\mu_{i, t}
\end{gathered}
$$

Where,

NMTPI $I_{i, t}$ is the total personal income for county $i$ in year $t$. Since the GDP data is not available for non-metro counties, I used total personal income to represent the county's total economic activity.

MGDP $_{i, t}$ is the GDP of the nearest metro area for county in year $t$.

DIS $\mathrm{i}_{\mathrm{i}}$ is the distance from county $i$ to its nearest metro area.

MPop $_{\mathrm{i}, \mathrm{t}}$ is the population of the nearest metro area for county $i$ in year $t$.

$\operatorname{MSchEn}_{\mathrm{i}, \mathrm{t}}$ is the K-12 enrollment of the nearest metro area for county $i$ in year $t$. 
WageGap $_{\mathrm{i}, \mathrm{t}}$ is the wage gap between county $i$ and its nearest metro area in year $t$, which equals the average weekly wages of the metro area minus the average weekly wages of the county $i$.

$\mathrm{COM}_{\mathrm{i}, \mathrm{t}}$ is the number of commuters between county $i$ and its nearest metro area in year $t$.

$\mathrm{BWM}_{\mathrm{i}}$ is a dummy variable. If county i borders at least one metro area, then $\mathrm{BWM}_{\mathrm{i}}=1$. Otherwise, $\mathrm{BWM}_{\mathrm{i}}=0$.

$\mathrm{BWLM}_{\mathrm{i}}$ is a dummy variable. There are three large metro areas on the border of the state of Indiana: Chicago, IL; Cincinnati, OH; and Louisville, KY. These areas, plus the Indianapolis metro area, have much stronger economic powers and more populations than any of the other metro areas in Indiana. The Indiana counties close to these areas could receive bigger metro spillover effects. As such, BWLM $\mathrm{i}_{i}=1$ if a county is next to one of these four large metro areas. Otherwise, $B W L M_{i}=0$.

Highway $_{\mathrm{i}}$ is a dummy variable used to capture whether county $i$ has an interstate highway that can be used to access to the nearest metro area. Highway ${ }_{i}=1$ if yes and Highway $_{\mathrm{i}}=0$ if no.

Two estimation methods are used in this study: random-effect general least square (GLS) and population-averaged Generalized Estimating Equation (GEE). Each method was used to run three regressions. The first regression was a benchmark regression used to test whether the metro economic power and non-metro location (i.e., Distance to Metro) mattered. The second regression was used to test all of the independent variables, which were reflections of the metro spillover effect. The last regression included all of the independent and dummy variables.

\section{Regression Results}

Table 2 displays the regression results of the random-effect GLS and population-averaged GEE models. Models I and IV are the benchmark regression models used to test whether the metro economy and distance to a metro area matter non-metro counties' total personal income. The results in both models prove that both variables are significantly related to non-metro counties' economic growth. Metro GDP had a positive impact, while distance had a negative impact. Such results strongly held in the other models (i.e., Models II, III, V, and VI). The results were also in line with previous studies (Polese, 2009; Patridge \& Rickman, 2008; Mulligan, 2013). However, unlike the findings presented by Patridge and Rickman, who proved the rural areas' poverty rates had a positive relationship to distance from metro areas, this paper found that the economic growth of non-metro counties, including rural areas, as 
measured by the growth of total personal income was negatively associated with distance to a metro area. A larger metro economic power could cause a bigger spillover effect to the surrounding non-metro areas, but the spillover effect would attenuate according to the non-metro counties' remoteness.

Models II and V were regressed using all of the independent variables. In addition to the metro's economic size and non-metro's location, metro population, metro K-12 school enrollment, the wage gap and number of commuters between metro and non-metro counties were further significant spillover factors to the non-metro's economy. A larger population is another reflector of metro areas' economic powers. As such, it draws the same positive impact to the surrounding areas as the metro GDP. Interestingly, the metro K-12 school enrollment showed a significant impact, as predicted, but had a dissuading impact on the non-metro's economic growth, which contradicted the hypothesis (H3). The possible explanation is as follows: although metro and non-metro areas' economies are interrelated, two regions are still in competition for potential resources and investments to grow their own economies. As stated before, education and human capital are key endogenous variables of economic growth (Romer, 1986; Krugman, 1991; Lucas, 2000; Frenken et al., 2007; Abel \& Gabe, 2011), for both metro and non-metro areas. An increasing K-12 school enrollment in the metro area, indicating a larger stock of potential human capital, will make it more favorable for potential resources and investments. As a result of needed resources and investments shifting to the metro areas, the non-metro's economy suffers.

The wage gap between metro and non-metro areas also had a significant, negative impact on the non-metro area's growth. A larger wage gap, which means a relatively higher rate of pay for work in the metro area, could reflect higher concentration of a larger number of better paying jobs as well as more skilled workers in metro areas. Without decent pay to attract skilled workers, non-metro areas cannot compete with metro areas in regard to potential resources and investments as explained previously. Therefore, their economy will face bleak futures. Similarly, the number of commuters is significantly and negatively associated with the non-metro areas' economic growth. Although more commuters on the road shows a strong tie between two areas, it could also reflect a tough economic condition and labor market in the non-metro areas, which forces people to travel to nearby metro areas to find jobs.

As we have seen so far, the metro spillover effects can be either positive or negative. The variables that imply metro economic powers, such as GDP and population, will have a positive influence on the non-metro's economy. However, the variables that indicate faster growth or better economic conditions in metro areas will show a reverse impact on non-metro areas' economies. Nonetheless, the metro spillover effects are derived effects that are not controllable by the non-metro areas. In order to advance their own economies, the non-metro areas need to focus on endogenous and controllable factors, such as education, business networks, technical efficiency and productivity, as well as infrastructure, as mentioned in the previous literature review.

Models III and VI show the complete regressions including all of the variables. All of the variables were significantly related to the non-metro areas' economic growth. According to 
the signs of the dummy variables, a county next to at least one metro area will receive more spillover effects from it/them. This result echoes the results in Models II and V which proved that distance to a metro area matters the non-metro counties' economic growth. The dummy variable of bordering a large metro area shows a negative impact on a county's economy, which is unexpected. Although the metro area's economic size matters, Indiana non-metro counties are far away from the center of the four largest metro areas in and around Indiana (Chicago, IL; Cincinnati, OH; Indianapolis, IN; and Louisville, KY). The average distance to a metro area in Indiana is about 36 miles, but the distance to the center of the four largest metro areas is about 65 miles. Therefore, the largest metro areas' spillover effects are much weakened over long distances. Finally, non-metro areas' economies can benefit from interstate highways that connect them to metro areas because interstate highways facilitate exchange of resources and information between metro and non-metro areas.

Table 2. Regressions of rural counties' economy and metro factors

\begin{tabular}{|c|c|c|c|c|c|c|}
\hline & $\begin{array}{l}\text { Model I } \\
\text { (GLS) }\end{array}$ & $\begin{array}{l}\text { Model II } \\
\text { (GLS) }\end{array}$ & $\begin{array}{l}\text { Model III } \\
\text { (GLS) }\end{array}$ & $\begin{array}{l}\text { Model IV } \\
\text { (GEE) }\end{array}$ & $\begin{array}{c}\text { Model V } \\
\text { (GEE) }\end{array}$ & $\begin{array}{c}\text { Model VI } \\
\text { (GEE) }\end{array}$ \\
\hline \multirow{2}{*}{ Constant } & $1220.61 * * *$ & $1454.71 * * *$ & $923.42 * * *$ & $1228.28 * * *$ & $1791.89 * * *$ & $1178.62 * * *$ \\
\hline & $(0.0000)$ & $(0.000)$ & $(0.000)$ & $(0.000)$ & $(0.000)$ & $(0.008)$ \\
\hline \multirow{2}{*}{ Metro GDP } & $0.0063 * * *$ & $0.0041 * * *$ & $0.0044 * * *$ & $0.0071 * * *$ & $0.0067 * * *$ & $0.0066 * * *$ \\
\hline & $(0.0000)$ & $(0.002)$ & $(0.001)$ & $(0.000)$ & $(0.000)$ & $(0.000)$ \\
\hline \multirow{2}{*}{$\begin{array}{l}\text { Distance } \\
\text { to Metro }\end{array}$} & $-12.019 * *$ & $-11.66^{* * *}$ & $-4.13 * * *$ & $-12.68^{*}$ & $-16.16^{* *}$ & $-7.50 * *$ \\
\hline & $(0.032)$ & $(0.004)$ & $(0.001)$ & $(0.053)$ & $(0.023)$ & $(0.037)$ \\
\hline \multirow{2}{*}{$\begin{array}{c}\text { Metro } \\
\text { Population }\end{array}$} & & $0.0014 * * *$ & $0.0014 * * *$ & & $0.0009 * * *$ & $0.0010 * * *$ \\
\hline & & $(0.000)$ & $(0.000)$ & & $(0.001)$ & $(0.000)$ \\
\hline $\begin{array}{l}\text { Metro } \\
\text { School }\end{array}$ & & $-0.0087 * * *$ & $-0.0083^{* * *}$ & & $-0.0071 * * *$ & $-0.0070 * * *$ \\
\hline Enrollment & & $(0.000)$ & $(0.000)$ & & $(0.000)$ & $(0.000)$ \\
\hline \multirow[b]{2}{*}{ Wage Gap } & & $-0.410 * * *$ & $-0.409 * * *$ & & $-0.464 * * *$ & $-0.456 * * *$ \\
\hline & & $(0.000)$ & $(0.002)$ & & $(0.000)$ & $(0.000)$ \\
\hline Commuters & & $-0.0168 *$ & $-0.0208 * *$ & & $-0.0441 * * *$ & $-0.0442 * * *$ \\
\hline
\end{tabular}


$(0.052) \quad(0.016)$

$(0.000)$

$(0.000)$

\begin{tabular}{|c|c|c|c|c|c|c|}
\hline $\begin{array}{c}\text { Border } \\
\text { with }\end{array}$ & & & $233.47 * * *$ & & & $250.140 * *$ \\
\hline Metros & & & $(0.002)$ & & & $(0.05)$ \\
\hline $\begin{array}{l}\text { Border } \\
\text { with a } \\
\text { Large }\end{array}$ & & & $-372.30 * * *$ & & & $-427.57 * *$ \\
\hline Metro & & & $(0.001)$ & & & $(0.028)$ \\
\hline Highway & & & $186.26^{*}$ & & & $230.56^{* *}$ \\
\hline to Metro & & & $(0.061)$ & & & $(0.047)$ \\
\hline Adjusted & & & & & & \\
\hline $\mathrm{R}^{2}$ & 0.1057 & 0.2344 & 0.2447 & & & \\
\hline Observations & 539 & 539 & 539 & 539 & 539 & 539 \\
\hline Wald & & & & & & \\
\hline Chi-square & $33.93 * * *$ & $99.02 * * *$ & $117.65 * * *$ & $40.91 * * *$ & $164.72 * * *$ & $169.42 * * *$ \\
\hline
\end{tabular}

Notes: p-values are shown in parentheses.

*** Indicates statistical significance at the 0.01 level.

** Indicates statistical significance at the 0.05 level.

* Indicates statistical significance at the 0.10 level.

\section{Conclusions and Discussion}

This paper examines metropolitan spillover effects on surrounding non-metro areas' economic growth. Past studies on rural and/or non-metro areas are ample, but most have focused on the endogenous factors within rural areas. In contrast, the scope of this paper has focused on the exogenous factors from nearby metro areas. Panel data from the state of Indiana between 2003 and 2013 was used to run six random-effect GLS and population-averaged GEE regressions. The results proved that a significant nexus exists between some metro factors and non-metro's economic growth. Above all, the metro's economic size and the non-metro counties' location are important to the non-metro counties' economy. It seems that a county without any proximity to a metro area could face more economic distress than a peer near a metro center. In addition, other metro social and economic factors can impact a non-metro's economic growth. Metro population, which can be considered to be a proxy of the metro economic size, is also positively related to the 
non-metro's economic well-being, but the metro K-12 enrollment, the wage gap and the number of commuters between the two areas does not contribute to the development of the non-metro's economy. Sharing a border with at least one metro area and having an interstate highway connecting it to the metro areas helps non-metro areas gain positive metropolitan spillover effects. However, sharing a border with a large metro area does not have a positive effect on non-metro areas as such non-metro areas are far away from the center of the large metro area.

The limitation of this paper is its scope of research target. This paper only used data from Indiana data to test the impact of the metro spillover effects to non-metro economic growth. The results could be more robust if the research was expanded to a larger scale of panel data. A further study can be conducted with more states or even the entire nation's data.

\section{References}

Abel, J. R., \& Gabe, T. M. (2011). Human capital and economic activity in urban America. Regional Studies, 45(8), 1079-1090. http://dx.doi.org/10.1080/00343401003713431

Aghion, P., Caroli, E., \& Garcia-Penalosa, C. (1999). Inequality and economic growth: the perspective of the new growth theories. Journal of Economic Literature, 37(4), 1615-1660. http://dx.doi.org/10.1257/jel.37.4.1615

Alesina, A., \& Perotti, R. (1996). Income distribution, political instability, and investment. European Economic Review, 40(6), 1203-1228. http://dx.doi.org/10.1016/0014-2921(95)00030-5

Barro, R. (1999). Inequality, Growth and Investment. NBER Working Paper 7038.

Beggs, J. J., Haines, V. A., \& Hurlbert, J. S. (1996). Revisiting the Rural - Urban Contrast: Personal Networks in Nonmetropolitan and Metropolitan Settings1. Rural Sociology, 61(2), 306-325. http://dx.doi.org/10.1111/j.1549-0831.1996.tb00622.x

Besser, T. L., \& Miller, N. J. (2013). Community matters: successful entrepreneurship in remote rural US locations. The International Journal of Entrepreneurship and Innovation, 14(1), 15-27. http://dx.doi.org/10.5367/ijei.2013.0104

Chandra, A., \& Thompson, E. (2000). Does public infrastructure affect economic activity? Evidence from the rural interstate highway system. Regional Science and Urban Economics, 30(4), 457-490. http://dx.doi.org/10.1016/S0166-0462(00)00040-5

Cheshire, P., \& Carbonaro, G. (1996). Urban economic growth in Europe: Testing theory and policy prescriptions. Urban Studies, 33(7), 1111-1128. http://dx.doi.org/10.1080/00420989650011537

Cortes, B. S., McKinnis, M., \& Davidsson, M. (2013). Industrial Composition, Local Fiscal Policy and Micropolitan Area Economic Growth. Mid-Continent Regional Science Association, 30. 
Deller, S. C., Tsai, T. H. S., Marcouiller, D. W., \& English, D. B. (2001). The role of amenities and quality of life in rural economic growth. American Journal of Agricultural Economics, 83(2), 352-365. http://dx.doi.org/10.1111/0002-9092.00161

Ding, L. (2002). Rural-urban income disparity: impact of growth, allocative efficiency, and local growth welfare. China Economic Review, 13(4), 419-429. http://dx.doi.org/10.1016/S1043-951X(02)00100-1

Eppler, U., Fritsche, U. R., \& Laaks, S. (nd.). Urban-Rural Linkages and Global Sustainable Land Use. Unpublished paper.

Fallah, B. N., \& Partridge, M. (2007). The elusive inequality-economic growth relationship: are there differences between cities and the countryside? The Annals of Regional Science, 41(2), 375-400. http://dx.doi.org/10.1007/s00168-006-0106-2

Fan, S., Hazell, P., \& Thorat, S. (2000). Government spending, growth and poverty in rural India. American Journal of Agricultural Economics, 82(4), 1038-1051. http://dx.doi.org/10.1111/0002-9092.00101

Fleisher, B., Li, H., \& Zhao, M. Q. (2010). Human capital, economic growth, and regional inequality in China. Journal of Development Economics, 92(2), 215-231. http://dx.doi.org/10.1016/j.jdeveco.2009.01.010

Florida, R., Mellander, C., \& Stolarick, K. (2008). Inside the black box of regional development-human capital, the creative class and tolerance. Journal of Economic Geography, 8(5), 615-649. http://dx.doi.org/10.1093/jeg/lbn023

Forbes, K. (1997). A Reassessment of the Relationship Between Inequality and Growth. Unpublished paper, MIT.

Frenken, K., Van Oort, F., \& Verburg, T. (2007). Related variety, unrelated variety and regional economic growth. Regional Studies, 41(5), 685-697. http://dx.doi.org/10.1080/00343400601120296

Glaeser, E. L., Kallal, H. D., Scheinkman, J. A., \& Shleifer, A. (1991). Growth in cities (No. w3787). National Bureau of Economic Research. http://dx.doi.org/10.3386/w3787

Goetz, S. J., Han, Y., Findeis, J. L., \& Brasier, K. J. (2010). US commuting networks and economic growth: Measurement and implications for spatial policy. Growth and Change, 4l(2), 276-302. http://dx.doi.org/10.1111/j.1468-2257.2010.00527.x

Krugman, P. (1990). Increasing returns and economic geography (No. w3275). National Bureau of Economic Research. http://dx.doi.org/10.3386/w3275

Li, H., \& Zou, H. F. (1998). Income inequality is not harmful for growth: theory and evidence. Review of Development Economics, 2(3), 318-334. http://dx.doi.org/10.1111/1467-9361.00045

Liu, Y., Wang, X., \& Wu, J. (nd.). Do bigger cities contribute to economic growth in surrounding areas? Evidence from county-level data in China. Unpublished paper. 
Lucas, R. E. (1988). On the mechanics of economic development. Journal of Monetary Economics, 22(1), 3-42. http://dx.doi.org/10.1016/0304-3932(88)90168-7

Lucas, R. E. (2000). Making a Miracle. Econometrica, 61(2), 251-72. http://dx.doi.org/10.2307/2951551

Mao, W., \& Koo, W. W. (1997). Productivity growth, technological progress, and efficiency change in Chinese agriculture after rural economic reforms: A DEA approach. China Economic Review, 8(2), 157-174. http://dx.doi.org/10.1016/S1043-951X(97)90004-3

Mankiw, N. G., Romer, D., \& Weil, D. N. (1990). A contribution to the empirics of economic growth (No. w3541). National Bureau of Economic Research. http://dx.doi.org/10.3386/w3541

McGranahan, D., \& Wojan, T. (2007). Recasting the creative class to examine growth processes in rural and urban counties. Regional Studies, 41(2), 197-216. http://dx.doi.org/10.1080/00343400600928285

Morrill, R., Cromartie, J., \& Hart, G. (1999). Metropolitan, urban, and rural commuting areas: toward a better depiction of the United States settlement system. Urban Geography, 20(8), 727-748. http://dx.doi.org/10.2747/0272-3638.20.8.727

Mulligan, G. F. (2013). The future of non - metropolitan areas. Regional Science Policy \& Practice, 5(2), 219-224. http://dx.doi.org/10.1111/rsp3.12005

North, D. C. (1955). Location theory and regional economic growth. The Journal of Political Economy, 243-258. http://dx.doi.org/10.1086/257668

Partridge, M. D., Ali, K., \& Olfert, M. (2010). Rural-to-Urban Commuting: Three Degrees of Integration. Growth and Change, 41(2), 303-335. http://dx.doi.org/10.1111/j.1468-2257.2010.00528.x

Partridge, M. D., \& Rickman, D. S. (2008). Distance from urban agglomeration economies and rural poverty. Journal of Regional Science, 48(2), 285-310. http://dx.doi.org/10.1111/j.1467-9787.2008.00552.x

Perotti, R. (1996). Growth, income distribution, and democracy: What the data say. Journal of Economic Growth, 1(2), 149-187. http://dx.doi.org/10.1007/BF00138861

Persson, T., \& Tabellini, G. (1994). Is inequality harmful for growth? The American Economic Review, 600-621.

Polèse, M. (2010). The wealth and poverty of regions: Why cities matter. University of Chicago Press.

Poon, J. P., Thai, D. T., \& Naybor, D. (2012). Social capital and female entrepreneurship in rural regions: Evidence from Vietnam. Applied Geography, 35(1), 308-315. http://dx.doi.org/10.1016/j.apgeog.2012.08.002 


\section{Macrothink}

Ring, J. K., Peredo, A. M., \& Chrisman, J. J. (2010). Business networks and economic development in rural communities in the United States. Entrepreneurship Theory and Practice, 34(1), 171-195. http://dx.doi.org/10.1111/j.1540-6520.2009.00307.x

Romer, P. M. (1986). Increasing returns and long-run growth. The Journal of Political Economy, 1002-1037. http://dx.doi.org/10.1086/261420

Simon, J. L. (1986). Theory of population and economic growth.

Zenou, Y. (2011). Rural-urban Migration and Unemployment: Theory and Policy Implications. $\begin{array}{llll}\text { Journal of } & \text { Regional } & \text { 65-82. }\end{array}$ http://dx.doi.org/10.1111/j.1467-9787.2010.00670.x

\section{Notes}

Note 1. "U.S. Metro Economies: Outlook-Gross Metropolitan Product, with Metro Employment Projections.” United States Conference of Mayors, November 2013.

Note 2. List of Metropolitan Areas in Indiana: Chicago-Naperville-Elgin, ${ }^{*}$ Cincinnati, ${ }^{*}$ Indianapolis-Carmel-Anderson, Louisville/Jefferson County, ${ }^{*}$ Fort Wayne, South Bend-Mishawaka, ${ }^{*}$ Evansville, ${ }^{*}$ Lafayette-West Lafayette, Elkhart-Goshen, Terre Haute, Bloomington, Muncie, Michigan City-La Porte, Kokomo, Columbus (*Metros with at least one county outside Indiana's boundaries; Source: Indiana Business Research Center using Census Bureau data).

\section{Copyright Disclaimer}

Copyright for this article is retained by the author(s), with first publication rights granted to the journal.

This is an open-access article distributed under the terms and conditions of the Creative Commons Attribution license (http://creativecommons.org/licenses/by/3.0/). 